\title{
Stickiness and the Adaptation of Organizational Practices in Cross-Border Knowledge Transfers
}

Robert J. Jensen

robertjensen@byu.edu

Gabriel Szulanski

Follow this and additional works at: https://scholarsarchive.byu.edu/facpub

Part of the Business Administration, Management, and Operations Commons

\section{Original Publication Citation}

Jensen, R.J., Szulanski, G. 24. Stickiness and the Adaptation of Organizational Practices in Cross-Border Knowledge Transfers. Journal of International Business Studies 35 (6): 58-523.

\section{BYU ScholarsArchive Citation}

Jensen, Robert J. and Szulanski, Gabriel, "Stickiness and the Adaptation of Organizational Practices in Cross-Border Knowledge Transfers" (2004). Faculty Publications. 436.

https://scholarsarchive.byu.edu/facpub/436 


\title{
STICKINESS AND THE ADAPTATION OF ORGANIZATIONAL \\ PRACTICES IN CROSS-BORDER KNOWLEDGE TRANSFERS
}

\author{
Robert Jensen \\ Marriott School, Brigham Young University \\ Department of Organizational Leadership and Strategy \\ 790 TNRB \\ Provo, UT 84602 \\ Tel: (801) 565-0027 \\ e-mail: rj33@email.byu.edu
}

Gabriel Szulanski

INSEAD

Department of Strategy and Management

Ayer Rajah Avenue

138676 Singapore

Tel : (65) 67995388

Fax: (65) 67995399

e-mail: gabriel.szulanski@insead.edu

June 11, 2004

Draft, please do not cite without explicit agreement from the authors

The authors acknowledge helpful comments and suggestions from Sidney Winter, Mauro Guillen, Marshall Meyer, Linda Cohen, anonymous reveiwers from JIBS and the Academy of Management's BPS Division, and the JIBS Departmental Editors Nicolai Juul Foss and Torben Pedersen. 


\title{
STICKINESS AND THE ADAPTATION OF ORGANIZATIONAL PRACTICES IN CROSS-BORDER KNOWLEDGE TRANSFERS
}

\begin{abstract}
The re-use of organizational practices in multiple locations is a fundamental way MNCs leverage knowledge to seek competitive advantage. Scholars approaching the issue of adaptation from both a market and an institutional perspective argue that, in order to achieve fit with the local environment, some degree of adaptation is advisable with the need for adaptation increasing as the institutional distance between source and recipient locations increases. However, arguments to date have examined the effect of adaptation primarily on a subsidiary's long term performance. A necessary precursor is to understand the effect of adaptation on the transfer process itself as transfer difficulty, or stickiness, may preclude the re-use of an organizational practice in the first place. In this paper, we explore how the adaptation of organizational practices affects the stickiness of a cross border transfer. We use structural equation modeling to analyze data from 122 internal transfers of best-practice. Contrary to expectation we find that adaptation significantly increases, rather than decreases, the stickiness of cross-border knowledge transfer.
\end{abstract}

Key words: Stickiness; Knowledge Transfer; Adaptation; Insitutional Theory; Multinational Corporation 
The effective deployment of products, technology, and knowledge in multiple locations has long been identified as a critical success factor of MNCs (Buckley \& Casson, 1976, Dunning, 1977, Hymer, 1976, Kogut \& Zander, 1993, Zaheer, 1995). Substantial attention has been devoted to prescribing adaptation as a necessary component in transfers of firm specific assets (Bartlett \& Ghoshal, 1989, Prahalad \& Doz, 1987). For example, it is often argued that consumer products, advertising campaigns, or distribution policies are more likely to function effectively when they are modified to reflect local market dynamics. Existing normative advice focuses on isolating criteria that should guide such adaptation with criteria including differences in culture (cf. Lemak \& Arunthanes, 1997), consumer preferences and needs (cf. Cui \& Liu, 2001), and labor practices (cf. Rosenzweig \& Nohria, 1994).

More recently a broader and more stylized perspective on adaptation has been developed by scholars of institutional theory. An institutional perspective suggests that legitimation is the main purpose and beneficiary of adaptation. In essence, adaptation is argued to increase both cognitive and normative legitimacy resulting in increased recipient motivation and ability to accept and utilize a transferred asset (Kostova, 1999, Kostova \& Roth, 2002, Kostova \& Zaheer, 1999).

In addition, institutional scholars offers the criterion of institutional distance as a factor moderating the influence of adaptation. Specifically, they suggest that legitimacy, both cognitive and normative, is directly related to institutional distance with such distance reducing the legitimacy of a transferred asset (Kostova \& Zaheer, 1999). Given that adaptation increases legitimacy by altering the asset to isomorphically fit the local environment it follows that as insitutional distance increases the benefit of adaptation is also likely to increase. 
While the earlier normative work on adaptation focused principally on the transfer of products and advertising campaigns (Cui \& Liu, 2001, Onkvisit \& Shaw, 1987, Ramarapu, Timmerman, \& Ramarapu, 1999), a recent trend, which includes the work of institutional scholars, has been to focus on the transfer of organizational practices ${ }^{1}$ (cf. Kostova \& Roth, 2002, Luo, 2000, Morosini, Shane, \& Singh, 1998, Westney, 1987). Such work has focused almost excluively on the final form the practice should take at the recipient site and the effect of adaptation on the ultimate success or failure of that practice. Such a focus, however, is likely to be premature. It assumes that the practice was transferred and implemented without difficulty. Research on the transfer process, however, indicates that such transfers are often very difficult, or sticky (Szulanski, 1996), with the incidence of transfer failure occuring frequently (Galbraith, 1990, Gupta \& Govindarajan, 2000). This article purposes to fill that gap by exploring the effect of adaptation on the difficulty, or stickiness, of transfers of organizational practices.

We explore this issue with the use of primary data collected through a two-step survey of 122 transfers of organizational practices, both domestic and international. The data, analyzed in a structural equation model, suggests that adaptation, contrary to expectation, significantly increases the difficulty of transferring organizational practices, even when controlling for the effect of institutional distance.

\section{TRANSFERRING ORGANIZATIONAL PRACTICES ACROSS BORDERS}

\section{Importance of Knowledge Utilization in an International Context}

\footnotetext{
${ }^{1}$ Organizational practices, or routines, can be conceived of as a web of coordinating relationships connecting specific resources, which, in operation, produce a firm's products in an ongoing fashion (Argote \& Ingram, 2000, Nelson \& Winter, 1982). This broad definition includes things such as manufacturing production lines, hiring practices, software development, etc.
} 
The effective sharing of organizational practices has fundamental competitive implications. For example, in the field of strategy there is widespread agreement that difficult to replicate knowledge assets, such as organizational practices and routines, are fundamental sources of competitive advantage in open economies. The long-term prosperity of firms operating in such environments seems to be increasingly predicated on their ability to identify and share those assets so that the firm can properly exploit them (Argote \& Ingram, 2000, Eisenhardt \& Martin, 2000, Gupta \& Govindarajan, 2000, Teece, Pisano, \& Shuen, 1997, Winter, 1995, Zander \& Kogut, 1995).

This is perhaps even more relevant for the MNC where technology and corporate knowhow are frequently shared across borders either between the parent firm and its subsidiaries, or between subsidiaries (Andersson, Forsgren, \& Pedersen, 2001). In this context the issue of the sharing of knowledge assets takes on even greater importance with some placing leveraging knowledge across borders at the center of the theory of the MNC (Anand \& Kogut, 1997, Kogut \& Zander, 1993).

\section{Stickiness and the Transferability of Knowledge}

Although knowledge assets in the form of organizational practices may be important for MNC success, they often do not transfer easily. Research into the process of knowledge transfer indicates that knowledge assets are often sticky (Szulanski, 1996), meaning that the transfer of such assets is difficult. For instance, Galbraith (1990) reports that many firms find intra-firm knowledge transfer much more difficult than expected and Gupta and Govindarajan (2000) describe how expectations of intra-firm knowledge transfers are often not met. Examples of specific difficult transfers abound, including IBM's ineffective transfer of reengineered logistics 
and hardware design processes (Anonymous, 1990) and General Motors inability to transfer knowledge between divisions (Kerwin \& Woodruff, 1992).

Stickiness in knowledge transfer, by definition, hinders knowledge from transferring within MNCs. If the success of MNCs is predicated on the ability to transfer firm specific assets and stickiness hinders that transfer, increased stickiness may increase the liability of foreignness (Hymer, 1976, Zaheer, 1995) decreasing the likelihood of a subsidiary's survival. It is therefore important to explore factors that increase or decrease stickiness when sharing organizational practices.

\section{Adaptation of Knowledge Assets}

The role and effect of adaptation is one of the most frequently discussed topics in the literature on transferring firm specific assets to different geographic markets (Bartlett \& Ghoshal, 1989, Kostova, 1999, Prahalad \& Doz, 1987) as adaptation is a central decision in an MNC's global integration strategy. There is significant agreement in the general adaptation literature, as well as in the literature focusing specifically on organizational practices, that some level of adaptation of firm specific assets is necessary to ensure the long term survival of the subsidiary (Bartlett \& Ghoshal, 1989, Luo, 2000, Morosini, Shane, \& Singh, 1998, Samiee \& Roth, 1992, Sorenson \& Weichmann, 1975, Sorge, 1991). However, the extent of adaptation is a secondary issue. Given the necessity of successfully completing the transfer of an organizational practice before it can be of value to the subsidiary, one needs to first ascertain the effect of adaptation on the transfer itself $^{2}$.

\footnotetext{
${ }^{2}$ Adaptation in this paper refers to adaptation occuring as part of the actual process of transfer prior to or during the transfer of the organizational practice. Adaptation can occur at any time but only that adaptation which occurs before or during the transfer is likely to affect the transfer itself.
} 
Stickiness and Adaptation in Cross-Border Knowledge Transfers

\section{The Effect of Adaptation on Stickiness}

\section{General Market Demands for Adaptation}

In the general adaptation literature the modal claim is that conditions vary widely in different locations creating pressure for adaptation as firms attempt to maximize their fit with the local environment (Bartlett \& Ghoshal, 1989, Lemak \& Arunthanes, 1997, Nohria \& Ghoshal, 1997). These pressures take the form of basic differences in culture (Buzzell, 1968, Hannon, Huang, \& Jaw, 1995, Lemak \& Arunthanes, 1997), governmental regulations (Kostova \& Roth, 2002), consumer preferences and needs (Bartlett \& Ghoshal, 1989, Cui \& Liu, 2001, Douglas \& Wind, 1987, Kashani, 1989, Lemak \& Arunthanes, 1997, Prahalad \& Doz, 1987), and labor practices (Rosenzweig \& Nohria, 1994), among others.

The goal of adaptation is typically to alter the asset being transferred so that it works within existing local cultural and market frameworks, allowing local actors to more easily accept the asset. Lack of fit may engender a rejection of the asset being transferred and, at the extreme, a rejection of the subsidiary attempting to use the asset (Sorge, 1991). Those who more recently have specifically examined the transfer of organizational practices use the same line of reasoning, predicting that the adaptation of organizational practices will increase recipient motivation, thereby increasing acceptance of the practice and decreasing the stickiness of the transfer (Griffith, Hu, \& Ryans, 2000, Kirkman, Gibson, \& Shapiro, 2001, Luo, 2000, Morosini, Shane, \& Singh, 1998).

\section{Institutional Demands for Adaptation}

The above arguments are developed further by scholars of institutional theory. Institutional theory posits that organizational practices are imbued with meaning and value that goes beyond 
the technical aspects of the particular organizational practice in question (Kostova, 1999, Selznick, 1957). Such meaning arises because the practices are embedded in and reflect the institutional environment where they were developed (Kogut, 1993, Meyer \& Rowan, 1977). As countries tend to be natural boundaries for many institutions (Orru, Bighart, \& Hamilton, 1991, Whitley, 1992) one would expect that transfers of practices across national boundaries would often require implementing the practice in an institutional context foreign to its origins (Kostova, 1999).

Differences between institutions create barriers to the acceptance and implementation of transferred practices. For instance, differences in cognitive institutional environments may create difficulties in understanding the nature and purpose of the practice due to differences in shared cognitive categories among different populations. For example, many U.S. firms have struggled with understanding the principles underlying some Japanese management practices. Likewise, if the normative institutions are sufficiently different there may be difficulties in accepting the practice because of culturally determined normative constraints that influence the appropriateness of various ways of doing things (Kostova \& Zaheer, 1999, Scott, 2001) ${ }^{3}$. For example, in many Arab nations HR programs designed to increase the percentage of women in upper management might not be readily accepted. As institutions vary from country to country one would expect differing degrees of transfer difficulty when transferring even the same practice to subsidiaries in different locations.

Institutional differences create pressures for isomorphic adaptation (DiMaggio \& Powell, 1983), pressures to make the transferred practices similar to those already in use in the local environment. Being similar (understandable, acceptable) grants legitimacy by the environment,

\footnotetext{
${ }^{3}$ The third of Scott's (2001) three types of institutions, regulatory institutions, is less relevant to this study as it primarily effects the ability to initiate transfers rather than creating difficulties influencing the process once the transfer is underway (Kostova \& Zaheer, 1999).
} 
a status that is posited to be imperative to the success and survival of organizations (Meyer \& Rowan, 1977). In a cross-border transfer situation legitimacy may thus be obtained by adapting transferred practices to the essential characteristics of the local institutional environment (Kostova \& Zaheer, 1999). One could thus argue that adaptation, by increasing the possibility of obtaining legitimacy, will decrease the stickiness of the transfer. These arguments, combined with those above based on market characteristics, lead to the first three hypotheses.

Hypothesis 1: Adaptation will have a positive effect on recipient motivation. Hypothesis 2: Recipient motivation will have a negative effect on stickiness (decreasing it).

Hypothesis 3: Adaptation will have a direct negative effect on stickiness (decreasing it). Hypothesis 4: Recipient motivation will partially mediate the effect of adaptation on stickiness.

Not all institutions, however, are equidistant from a source's institutional environment (Hofstede, 1991) and as the distance (i.e.; differences) increases so does the pressure for adaptation (Kostova \& Zaheer, 1999) both in terms of legitimacy, and hence motivation, and in terms of the cognitive ability to understand the practice. For instance, people in Mexico share more of the same cognitive schemas and categories with people in Columbia than they do with people in Mongolia. In this case the cognitive institutions in Mongolia would be more distant, exerting more pressure for adaptation on a practice originating in Mexico, than would be those in Columbia. The same pattern is likely to occur for normative institutions. Absent adaptation, one would expect institutional distance to both decrease motivation and increase stickiness. As the distance increases legitimacy is likely to decrease, thus making it more difficult to understand and correctly implement the intent of the practice.

It follows, then, that as institutional distance increases it also increases the potential benefit of adaptation (Kostova \& Zaheer, 1999). For instance, the institutional distance between 
Mexico and Columbia is likely to be small, with difficulty arising from differences between those institutions also likely to be small. However, as the institutional distance between Mexico and Mongolia is large the difficulty attributable to the distance is also likely to be large. As adaptation modifies the practice to fit with local institutions there is much greater latitude for decreasing stickiness in the latter case than in the former as there is more distance related stickiness to be reduced. This leads to the next set of hypotheses.

Hypothesis 5: Institutional distance will have a negative effect on recipient motivation. Hypothesis 6: Institutional distance will have a positive effect on stickiness (increasing it).

Hypothesis 7: Institutional distance will moderate the relationship between adaptation and recipient motivation (the interaction term will increase recipient motivation). Hypothesis 8: Institutional distance will moderate the relationship between adaptation and stickiness (the interaction term will decrease stickiness).

\section{METHOD}

\section{Sample and Research Method}

The transfer of best practices (O'Dell, Grayson, \& Essaides, 1998) provides a propitious setting to observe transfers of knowledge within organizations. Data were collected through a two-step survey. The first step of the survey asked companies to provide a list of transfers for study that included sufficient detail about the parties involved in those transfers (i.e., respondents). More than 60 companies, with varying degrees of experience in the transfer of practices, expressed interest. Of that group, 12 were able to provide such a list. Of the 12 , only eight provided entries of sufficient quality to warrant continuation of their involvement in the research. The eight companies were: AMP, AT\&T Paradyne, British Petroleum, Burmah Castrol, Chevron Corporation, EDS, Kaiser Permanente, and Rank Xerox. All are large firms with yearly turnover ranging from over $\$ 100$ million to over $\$ 100$ billion, employing from 12,000 to over 100,000 employees. 
The second step of the survey was devised to analyze specific transfers. The final sample consisted of 271 returned questionnaires, spanning 122 separate transfers of 38 practices ${ }^{4}$, for a response rate of $61 \%$. The transfers are primarily lateral, from subsidiary to subsidiary, and involve 19 countries from nearly all world regions including: Australia, Austria, Belgium, Brazil, Columbia, Denmark, England, France, Germany, Holland, Italy, Malaysia, Mexico, New Zealand, Scotland, Singapore, South Africa, Thailand, and the United States.

To obtain a balanced perspective on each transfer separate questionnaires were sent to a source, a recipient, and a third party to the transfer and filled out on location at their respective units. Triangulation using all three respondent types was considered appropriate as quality data on intra-firm transfers of practices has traditionally been very difficult to obtain. The level of analysis is the transfer between units. However, it is difficult to assess the perceptions of "units" as the perceptions of individual respondents within a particular unit are likely to be only partially representative of their unit's overall perception. Moreover, concerning a specific transfer, the perceptions of various units are likely to overlap significantly as perceptions are often developed from depersonalized presumptive rationales based on lessons from prior history, affiliation with specific social categories, formal roles, and organizational rules regarding transaction norms (Kramer, 1999). Thus, given sampling restrictions and in order to obtain the most complete and unbiased data possible we considered it more appropriate to triangulate by obtaining responses from individuals in three different perspectives rather than sampling more heavily within a single perspective.

\footnotetext{
${ }^{4}$ The sample contained both technical and administrative practices. Examples of technical practices are software development procedures and drawing standards. Examples of administrative practices are upward appraisal and activity-based costing (ABC). Full disclosure of the practices studied is precluded by a guarantee of confidentiality.
} 
The respondents comprised 110 source units, 101 recipient units and 60 third parties. Average item non-response was lower than 5\%. An average of 2.2 questionnaires was received for each transfer studied. To provide transfers for study, companies were directed to search for transfers of practices that could not be performed by a single individual but rather required the involvement of a group.

\section{Construction of Measures}

As well as triangulating the respondents to increase the quality of the data, multiple-item scales were developed for all constructs except institutional distance. This helps to ensure the reliability and validity of the measurement system. Except for the institutional distance measure, little empirical precedent was available to guide the development of the measures (see Zander \& Kogut, 1995 for an exception). A broad and thorough literature review informed the generation of the initial constructs and the a priori assignment of items to measure those constructs. Indepth clinical work, consultation with subject experts, and feedback obtained when piloting the survey helped refine the choice of constructs, identify the most relevant items for those constructs and select their proper wording given the empirical context. Some items were discarded, but not re-assigned, after the full data set was obtained; the a priori assignment of items was preserved for all constructs except adaptation and institutional distance, which we introduced ex-post. Following Nunnally's (1978) recommendation, construct scores were computed by summing the standardized item scores. Below we detail the operationalization of the constructs for this paper. 


\section{Stickiness}

Stickiness refers to the difficulty of transferring knowledge. The measure of stickiness used in this paper refers to stickiness during the central stages, the implementation and ramp-up stages, of the transfer process (Szulanski, 2000). In essence this covers the time from when the source begins transferring to the recipient until the recipient achieves comparable results. Prior to the implementation period the recipient is in search for a practice to transfer and after the recipient achieves comparable results the recipient is engaged in the institutionalization of the practice. These time periods are outside of the scope of this paper because adaptation doesn't usually occur until the source is in contact with the recipient and hence there is an environment to adapt to. Likewise this paper does not consider the institutionalization phase of a transfer as the recipient has generally either abandoned the transfer or achieved comparable results before this period begins. This gives an indication of the result of the transfer process, which is the result in question here rather than the long term success of the practice at the subsidiary site.

The measure of stickiness has 18 items measuring the extent of problems in the transfer and the extent of eventfulness. Specific problems assessed were difficulties in communication between the source and recipient, difficulties in assessing the requirements of the knowledge and the expertise of the source, difficulties in the relationship between the source and recipient, difficulties in implementing the knowledge and achieving satisfactory performance, and the need to develop ad hoc solutions to various implementation problems. Beyond measuring perceptions of difficulty we also measured whether or not milestones, budgets, and expectations were met.

The eventfulness measure discriminates between the base costs of a transfer, those that would exist even without difficulty, and the actual difficulty arising from the transfer. It does so by measuring the escalation of transfer related problems beyond those which are diagnosed 
easily and resolved routinely by those directly involved with the transfer. The word eventfulness is used because escalated problems tend to be noticed more broadly because they interrupt the assumed flow of the transfer (Zeigarnik, 1967), are more likely to create a distinct moment of difficulty in the transfer (Gilovich, 1991), and thus are more likely to contribute to the overall perception of difficulty and to the intensity of efforts exerted to resolve the problem (cf. March \& Simon, 1958). Other things being equal, a transfer is more likely to be perceived as difficult or sticky when efforts to resolve transfer problems become noteworthy. All construct items are listed in the appendix.

\section{Adaptation}

The adaptation of the practice being transferred refers to differences introduced between the original practice and the replica. A measure of adaptation should therefore be sensitive to differences between the features of the replica and those of the original template.

Communication scholars suggest that there are two types of adaptations, general ones that affect the comprehensive meaning of the practice or specific ones that affect aspects of the practice while preserving its overall meaning (Muchinsky, 1977, Roberts \& O'Reilly, 1974, Shannon \& Weaver, 1949). Our measure consists of seven items five of which assess levels of general modifications while two assess specific modifications. The specific wording of the items can be found in the appendix.

\section{Institutional Distance}

Our measure for the institutional distance between source and receiver countries is the Kogut and Singh Cultural Distance Index (1988). This index has been extensively used in the International 
Business literature (e.g. Barkema, Bell, \& Pennings, 1996, Luo, 2000, Morosini, Shane, \& Singh, 1998, Park \& Ungson, 1997) as well as in related fields like international marketing (e.g. Gielens \& Dekimpe, 2001) and has been found to be robust. The index is derived from Hofstede's indices (1991) of cultural dimensions i.e.; power distance, individualism, uncertainty avoidance, and masculinity/femininity. The scores for each country on the four dimensions were obtained from Hofstede (1991).

Kostova (1999) has recommended using a more holistic measure of institutional distance that involves taking practice specific measures of the regulatory, cognitive, and normative institutions in both the source and recipient country. The Kogut and Singh (1988) index adequately captures cognitive and normative institutions (Kostova, 1999) which are the applicable institutions to measuring the difficulty of transferring organizational practices. Regulatory institutions are specifically applicable to patterns of adoption rather than implementation (Kostova, 1999). In addition, as most practices, including those in this study, are typically unknown outside of the functions directly involved with them a culturally based measure, such as the Kogut and Singh Index (1988), is more suitable to capturing underlying cognitive and normative frameworks that may not be as conscious and well communicated as those required by Kostova and Roth's (2002) measure. Finally, the Kogut and Singh (1988) index, being a broadly based cultural measure, allows for easy comparison across organizations and practices.

\section{Recipient Motivation}

The motivation of the recipient refers to the recipient's desire to implement the practice being transferred. Motivation as a source of difficulty in knowledge transfer is well documented (e.g. 
Hayes \& Clark, 1985, Katz \& Allen, 1982) with lack of motivation resulting in passivity, feigned acceptance or implementation (Jensen, Szulanski, \& Casaburi, 2004), hidden sabotage, intentionally slow implementation, or outright rejection of the practice (cf. Zaltman, Duncan, \& Holbek, 1973). The measure used in this study consists of 14 binary items measuring whether the recipient saw benefit in undertaking specific transfer related actions. The final measure is constructed by summing the individual binary scores. The items comprising the measure can be found in the appendix.

\section{Control Variable: Characteristics of the Practice}

Previous work on stickiness (Szulanski, 1996) has indicated that the characteristics of the practice, particularly causal ambiguity, are among the most important predictors of stickiness. As such we include causal ambiguity in the model as a control variable. Causal ambiguity refers to inherent and irreducible uncertainty as to precisely what the factors of production are and how they interact (Lippman \& Rumelt, 1982). In such a situation it is impossible to produce an unambiguous list of the factors of production and, as such, impossible to measure the contribution of each factor, making transfer of such a practice difficult (Rumelt, 1984). The measure of causal ambiguity specifically addresses gaps in understanding the causes of success and failure of particular practices. The measure has eight items with the specific item wording located in the appendix.

\section{Construct Analysis}

Table 1 summarizes the measurement performance of the variables ${ }^{5}$.

\footnotetext{
${ }^{5}$ When constructing path analytic models it is customary to use confirmatory factor analysis (CFA) to establish the convergent and discriminant validity of the constructs. However, a widely used rule of thumb is that the sample size should be 10-20 times the number of parameters being estimated in the model (Kline, 1998),
} 
Insert Table 1 About Here

Reliability and unidimensionality were evaluated separately for each construct (Gerbing \& Anderson, 1988). Cronbach's alpha was used as a measure of reliability because it provides a lower bound to the reliability of a scale and is the most widely used measure (Nunnally, 1978). All scales had an alpha greater than .70 providing an adequate level of reliability for predictor tests and hypothesized measures of a construct (Nunnally, 1978, pgs. 245-246).

Unidimensionality was conducted through comparison of Cronbach's alpha with the theta coefficient obtained through factor analysis. Both were within .02 of each other for all constructs indicating acceptable unidimensionality (Armor, 1974, Carmines \& Zeller, 1979, Zeller \& Carmines, 1980). Finally, all variables meet reasonable assumptions of normality (see Table 1 for skewness and kurtosis values). Although the variable for institutional distance indicated potential difficulties with the normality assumption, residual probability plots indicated assumptions of normality were warranted.

Discriminant validity was evaluated for all construct pairs by examining the observed correlation matrix of the constructs. If the correlation between constructs $i$ and $j$ is 1 , (i.e., if constructs $\mathrm{i}$ and $\mathrm{j}$ are perfectly correlated), the observed correlation should be $\left(\alpha_{\mathrm{i}}{ }^{.5} *\left(\alpha_{\mathrm{j}}{ }^{5}\right)\right.$ where $\alpha_{i}$ and $\alpha_{j}$ are the reliability coefficients for the constructs. In practical terms, testing for discriminant validity entails computing the upper limit for the confidence interval of the

requiring a significantly large sample if multi-item scales are used. As research into the transfer of organizational practices is relatively new and single item scales are typically unreliable we opted to use multiple item scales despite the fact that large samples of intra-firm practice transfers are rare and difficult to obtain. As the use of CFA results in unstable estimates when the sample size is small compared to the number of parameters being estimated (Kline, 1998) we chose to use other traditional methods to establish construct validity before specifying the structural equation model. 
observed correlations and testing whether this limit is smaller than the maximum possible correlation between the scales as computed from their reliability coefficients ${ }^{6}$. Table 2 reports the correlations for all the variables. All construct pairs met the discriminant validity test at $\mathrm{p}<$ .0015 or better, lessening concerns for common method bias.

Insert Table 2 about here

\section{Assumptions for the Analysis}

Cross-sectional comparison of transfers is warranted.

Leonard-Barton (1990) argues that it is necessary to measure multi-item constructs at a "defined point" in time if meaningful comparisons are wanted, because the meaning of complex constructs depends on when during a transfer they are measured. As point of reference for her study she selected the "very first use of the technology in a routine production task" as the anchor point. She chose that point because it could be identified with a "satisfactory degree of precision.” In this study, all questionnaires were completed within a narrow ${ }^{7}$ band of 3.5 months, which started 5 months after the first day the practice was first put to use by the recipient. Thus,

\footnotetext{
${ }^{6}$ We also conducted discriminant validity tests using confirmatory factor analysis. No confidence interval for any latent factor correlation included 1.0. This further corroborates the conclusion that all factors are indeed separate and distinct.

${ }^{7}$ Such a band of 3.5 months can be considered narrow, because it means that all transfers were sampled early on in the integration stage which has been documented to last between 1.5 to 2 years.
} 
all transfers are at a defined and comparable point in time. Comparison across transfers is thus considered appropriate.

\section{Structural Model}

Structural equation modeling is particularly suitable for testing models that are path analytic, especially those including mediating variables, allowing for simultaneous estimation of the relationship between all of the specified variables in the model. Because our model included multiple mediating relationships we deemed a structural equation model appropriate.

Figure 1 depicts the model of relationships between adaptation, stickiness, recipient motivation, institutional distance, the interaction term between institutional distance and adaptation $^{8}$, and causal ambiguity. The SEPATH module of Statistica was used for the analysis with parameter estimates being obtained using the maximum likelihood estimator. The overall fit of the model was good with a chi-square statistic of 4.69 with 2 degrees of freedom $(p<.10)$ for a chi-square/degrees of freedom ratio of 2.35. The CFI and RMSEA statistics also signified an adequate fit reporting .989 and .089 respectively.

\section{Insert Figure 1 About Here}

\section{RESULTS}

\footnotetext{
${ }^{8}$ The interaction term, following Ping (1995), is constructed by multiplying the two latent variables. Anderson and Gerbing (1988) suggest that such an approach is justified when the latent variables are unidimensional as they are here.
} 
As figure 1 shows, we found support for only two of the seven hypotheses with two reporting significant and opposite results. Table 3 summarizes the direct relationships tested in the model while table 4 indicates any mediating effect of recipient motivation by decomposing the total effect of each parameter into direct and indirect effects ${ }^{9}$.

Insert Table 3 About Here

Insert Table 4 About Here

As indicated, and in line with theories of environmental fit including institutional theory, the results suggest support for hypothesis 1 , that recipient motivation decreases difficulty, or stickiness, when transferring organizational practices. However, in contrast there is little evidence for hypothesis 2 , that adaptation increases the recipient's motivation to implement the practice. There is also no evidence for hypothesis 3 , that adaptation decreases stickiness. In fact, the results strongly suggest the opposite, that adaptation significantly increases stickiness. Moreover, institutional distance does not appear to moderate the effect of adaptation, either on recipient motivation (hypothesis 7) or stickiness (hypothesis 8), although it does, as hypothesized, have a significant negative effect on recipient motivation (hypothesis 5). However, contrary to expectations the results suggest that increasing institutional distances decreases, rather than increases stickiness (hypothesis 6). Finally, there is no evidence that recipient models.

${ }^{9}$ See Kline (1998, ch. 5) for the methodology behind testing mediating effects in structural equation 
motivation mediates between adaptation and stickiness (hypothesis 4), although it does appear to mediate between institutional distance and stickiness.

Possible explanations for the finding that adaptation significantly increases stickiness will be explored in the discussion. A possible explanation for the finding that institutional distance decreases stickiness could be that as a practice becomes less cognitively understandable due to institutional differences sources are less, rather than more, likely to adapt. Despite pressures for legitimacy subsidiaries may realize the potential difficulty in copying organizational practices and opt for less adaptation or possibly delayed adaptation. This explanation was tested by respecifying the model with a path from institutional distance to adaptation. While the sign was negative, suggesting less adaptation across greater institutional distances the coefficient was not significant.

\section{Robustness of the Results}

Further analyses were conducted to explore the stability of the coefficients. First, following the procedures outlined in the manual for the SEPATH module of Statistica, a Monte Carlo analysis was conducted to determine if the parameter estimates are robust to small perturbations of the sample. The simulation conducted 1000 iterations using a random seed generator to generate simulated populations from the data. The analysis then utilized the correlation matrix and the maximum likelihood estimator to derive the parameter estimates for each simulated iteration. All previously reported parameters were within a 95\% confidence interval of the mean of the 1000 iterations indicating that the parameters are sufficiently robust.

Second, the same model was run on data where the three respondent types (source, recipient, and third party) were aggregated for each transfer rather than treated as separate data 
points. While this reduced the sample size significantly the coefficients remained stable and signficant except for the effects of causal ambiguity and institutional distance on stickiness.

\section{Alternative Explanations}

One potential alternative explanation to the findings is that rather than adaptation in general causing stickiness incorrect adaptation is culpable. There are two aspects of this argument. First, the adaptation may be appropriate but insufficient. If this argument is true as adaptation increases we should find the level of stickiness decreasing. The findings do not support this hypothesis. Second, adaptation may be sufficient in magnitude but innappropriate. The crux of this point of view is that the environment, rather than the characteristics of the practice, are still the critical element during a transfer process but that the environment must be sufficiently understood.

However, anecdotal evidence from a number of firms that consistently and successfully transfer organizational practices suggests that the characteristics of the practice being transferred are often given greater weight during the transfer process than the relevant charateristics of the local environment with firms discouraging adaptation efforts completely or at least until the practice is fully transferred (Anonymous, 1999, Anonymous, 1997, McDonald, 1998).

Moreover, the argument in favor of "correct" adaptation assumes that the relevant characteristics of the local enviornment can be adequately enumerated ex-ante. However, research suggests that the relevant environment for the purpose of adaptation typically turns out to be different from the one that is anticipated (Westney, 1987). Furthermore, Penrose (1959), in an argument echoed by Burgelman (1983), contends that the relevant environment can only be fully determined ex-post. Given that adaptation involves not just adaptation to an ambiguous 
enviornment but mutual adaptation between the practice and the environment even local, experienced management is likely to incorrectly understand the relevant charateristics of the local environment that should be adapted to (Leonard-Barton, 1988). In such a situation many adaptation efforts will be misadapted thereby increasing stickiness rather than decrease it.

One other alternative explanation is reverse causality. Rather than adaptation increasing stickiness, stickiness increases adaptation. This is a serious contender that we cannot rule out with the exploratory data at hand as a non-recursive path model cannot be adequately identified. It seems likely that there is at least some reverse causality. A potentially common method for overcoming unexpected difficulty in implementing a new practice at a recipient site may be to alter it to fit the site. However, anecdotal evidence from a number of firms suggests that the finding that adaptation leads to stickiness occurs in real firms. For instance, in some companies heavily involved in the transfer of practices a heuristic seems to have developed where, in the transfer process, firms forego even the smallest modification unless it is absolutely necessary. This can be seen in Intel's “Copy Exactly” philosophy for building semiconductor plants (Iansiti, 1998) and Rank Xerox's policy of forcing country subsidiaries to follow best practice "down to the last detail" until they achieve similar performance (Anonymous, 1997).

Adaptation creating stickiness in the transfer process is also a commonly recognized problem in franchising where organizational practices are transferred on a regular basis (Bradach, 1998, Seid \& Thomas, 2000). An example of a franchising policy intended to overcome this problem is Great Harvest's learning covenant that holds new franchisees to the "tiniest letter" of their promises to follow the original system for at least one year following the transfer (Anonymous, 1999). Thus, even if some amount of reverse causality is present it is not likely to remove the effect of adaptation suggested by the results. 


\section{DISCUSSION AND CONCLUSION}

For organizations, sharing knowledge assets through the transfer and re-use of organizational practices has emerged as a critical component of competitive advantage. This is even more visible in the International Business arena where the transfer of firm specific resources, especially knowledge (Buckley \& Casson, 1976), has long been predicted as a key for the success of MNCs (Dunning, 1977, Hymer, 1976, Kogut \& Zander, 1993). One of the most discussed issues in the re-use of firm specific assets across national borders is the extent to which those assets should be adapted to more closely fit the local environment. This article examines the effect of adaptation on the difficulty, or stickiness, of the transfer process.

In specific, following institutional theory, we argue that adaptation will increase legitimacy in normative institutions thereby increasing recipient motivation which, in turn, decreases transfer stickiness. As well, adaptation may render practices cognitively similar to local frameworks increasing legitimacy in cognitive institutions thereby making the practice easier to understand and implement. Adaptation is thus hypothesized to have both a direct and indirect effect, with recipient motivation acting as a mediating variable, decreasing the stickiness of the transfer. Also following institutional theory we argue that institutional distance will moderate the relationship between adaptation and both recipient motivation and stickiness additionally increasing recipient motivation and decreasing stickiness the further the institutional distance.

Our analysis, which relies on primary data collected through a two-step survey of 122 transfers of organizational practices, both domestic and international, shows that, contrary to expectation, adaptation significantly increases the difficulty of transferring organizational 
practices rather than decreasing it. Recipient motivation does not mediate the relationship and institutional distance, also contrary to expectation, does not lessen the impact of adaptation. The results are surprising and at first glance seem to belie much of the previous work on adaptation.

The results, however, may be highlighting a discrepancy in previous research rather than directly disagreeing. Specifically, this study is among the first to explore the effect of adaptation on stickiness rather than on adoption patterns or success/failure of the subsidiary. As such, it may be that institutions and other market based forces calling for adaptation, which have been considered pervasive influences in cross-border transfers of knowledge, are less influential during the actual transfer than previously considered. This suggests that previous theories may still be correct but their applicability may increase during the later stages of a transfer.

Anecdotal evidence provides some insight into what may be driving the results reported here. As mentioned earlier, some companies heavily involved in the transfer of practices a heuristic seems to have developed where, in the transfer process, firms forego even the smallest modification unless it is absolutely necessary. This can be seen in Intel's "Copy Exactly" philosophy for building semiconductor plants (Iansiti, 1998), Rank Xerox’s policy of forcing country subsidiaries to follow best practice "down to the last detail" until they achieve similar performance (Anonymous, 1997), and Great Harvest's learning covenant that holds new franchisees to the "tiniest letter" of their promises to follow the original system for at least one year following the transfer (Anonymous, 1999).

In these anecdotal examples the underlying logic is that modifications of even moderately complex practices quickly lead to incomparability with the original, which creates difficulty as the original can no longer be used as an example, or template (Nelson \& Winter, 1982), to guide the transfer effort. While this may not be a problem with the transfer of simple knowledge, the 
experience of many firms seems to indicate that transfers are often a difficult process requiring an iterative attempt to recreate the practice being transferred (Jensen, Szulanski, \& Casaburi, 2004, Winter \& Szulanski, 2001). In such cases incomparability with the original practice may substantially increase the difficulty of the transfer.

This has direct managerial implications for the control of intra-MNC knowledge flows. The results suggest that stickiness, and the effect adaptation has on it, must be considered prior to, or at least in conjunction with, considerations of the ultimate form a practice should take at a subsidiary. Moreover, it appears that, at least in terms of transferring organizational routines and practices, the characteristics of the practice, such as comparability with the original, may have more weight in determining the difficulty of the transfer effort than do motivational issues or issues of legitimacy in the local environment.

Of course, adaptation is likely to be both necessary and desirable at some point following the transfer. Previous research, including that in institutional theory, has established the importance of fit with the local environment suggesting that those who do not achieve fit risk rejection of the transferred practice and, at the extreme, risk the survival of the subsidiary (Sorge, 1991). Despite the ultimate need for adaptation, however, our findings suggest that such adaptation should potentially be delayed until the practice has been completely transferred and implemented.

While the results are significant the limitations of the study suggest that they should be used with caution. First, it bears repeating that the findings are exploratory. There are only eight firms in the sample and not all of the transfers are cross-border. Thus, results should be applied to a strictly multinational context with caution. Second, the study is cross-sectional in design, suggesting that strong causal inferences may not be warranted. To more fully explore the effect 
of institutions on the process of transfer one would need to use a longitudinal design that includes the process of institutionalizing a transferred practice. As mentioned previously, it is likely that adaptation, while undesirable during the implementation and ramp-up phases may become desirable as time passes.

Third, it is possible, perhaps even likely, that adaptation has simultaneous and opposite effects, both making it easier to initially understand and implement a practice while also making it more difficult to compare it with the original. While the analysis in this paper suggests that the net effect is toward adaptation increasing difficulty, future research may be able to separate the two effects, potentially testing for contingency factors that may shift the sign of the net effect.

Finally, it may also be that current measures of institutions, including the measure used in this study, are too blunt to effectively pick up a fine-grained effect of institutions. This may be why cultural distance as a measure of institutional distance did not pick up an effect while Kostova and Roth's (2002) practice specific measure of distance between cognitive institutions did. Future studies may want to include finer grained measures while maintaining comparability across organizations and practices.

Despite the effect Kostova and Roth (2002) found for cognitive institutions, however, our mixed results concerning the effect of institutions are very similar to previous findings. For instance Kostova and Roth (2002) did not find an effect for normative or regulatory institutions while finding that the effect of the relationship between the firm and subsidiary was significantly greater than that of cognitive institutions. Likewise, Westney (1987) found that competition among alternative models being transferred played a greater part in the adaptation of practices transferred from the U.S. to Japan than did local institutions. It may be that institutions play a role in the efficiency of the transfer as well as the form of the final practice. However, it appears 
that more immediate concerns, such as characteristics of the practice, may take precedence and have a far greater impact on the transfer than initially assumed.

The potential theoretical and managerial implications of the results highlight the need to further examine the process of transferring knowledge assets across borders. Given that the sharing of firm specific assets seems to be a pre-requisite for MNC success, mechanisms that allow for successful sharing of knowledge and actions that may increase the difficulty of the transfer are essential to understand. Adaptation appears to be one of those actions. However, it is by no means clear that adaptation is inherently detrimental. Instead, timing may be critical with adaptation increasing in appropriateness following the transfer. It may also be that the locus of adaptation (source or recipient initiated) moderates the relationship between adaptation and the stickiness of the transfer. Finally, various mechanisms of transfer (transfer of personnel vs. use of written materials) may influence the ability to successfully adapt the practice. Hopefully future research will more fully elucidate the role of adaptation in the stickiness of transfers of organizational practices.

\section{Table 1: Construct Measurement}

\begin{tabular}{|c|c|c|c|c|c|c|c|}
\hline Construct & Description & $\begin{array}{c}\text { Cronbach } \\
\alpha\end{array}$ & Itms & $\begin{array}{l}\text { Valid } \\
\mathrm{N}\end{array}$ & $\begin{array}{l}\text { Avg. } \\
\text { Inter item } \\
\text { Corr. }\end{array}$ & Skwness & Kurtosis \\
\hline $\begin{array}{l}1 \text { Institutional } \\
\text { Distance }\end{array}$ & $\begin{array}{l}\text { Cultural distance between the } \\
\text { countries housing the source and } \\
\text { recipient units }\end{array}$ & & 1 & 268 & & 2.04 & 2.81 \\
\hline 2 Causal ambiguity & Depth of knowledge & .86 & 8 & 250 & .45 & .19 & -.74 \\
\hline $\begin{array}{l}3 \text { Recipient's } \\
\text { motivation* }\end{array}$ & $\begin{array}{l}\text { Motivation of the recipient unit } \\
\text { to support the transfer }\end{array}$ & .93 & 14 & 271 & .48 & -.31 & -1.27 \\
\hline 4 Adaptation & $\begin{array}{l}\text { Degree of difference between } \\
\text { the replica and the template. }\end{array}$ & .76 & 7 & 203 & .32 & .03 & -.43 \\
\hline 5 Stickiness & $\begin{array}{l}\text { The degree of difficulty } \\
\text { encountered during the } \\
\text { knowledge transfer. }\end{array}$ & .84 & 18 & 220 & .23 & .14 & -.50 \\
\hline
\end{tabular}

* This scale is composed of binary items. It qualifies marginally as a Guttman scale. 
Table 2: Pearson Product-Moment Correlations

\begin{tabular}{lccccccc}
\hline & Mean & s.d. & 1 & 2 & 3 & 4 & 5 \\
\hline 1 Institutional Distance & 11.22 & 24.59 & 1.00 & & & & \\
2 Causal Ambiguity & 0.01 & 5.69 & $0.16^{*}$ & 1.00 & & & \\
3 Recipient Motivation & 7.85 & 4.92 & $-0.28^{*}$ & $-0.28^{*}$ & 1.00 & & \\
4 Adaptation & -0.27 & 4.31 & 0.11 & $0.53^{*}$ & $-0.24^{*}$ & 1.00 & \\
5 Stickiness & 1.38 & 8.59 & -0.01 & $0.50^{*}$ & $-0.29 *$ & $0.71^{*}$ & 1.00 \\
\hline * significant at $\mathrm{p}<.05$ & & & & & & &
\end{tabular}

Figure 1 Structural Model with Standardized Coefficients

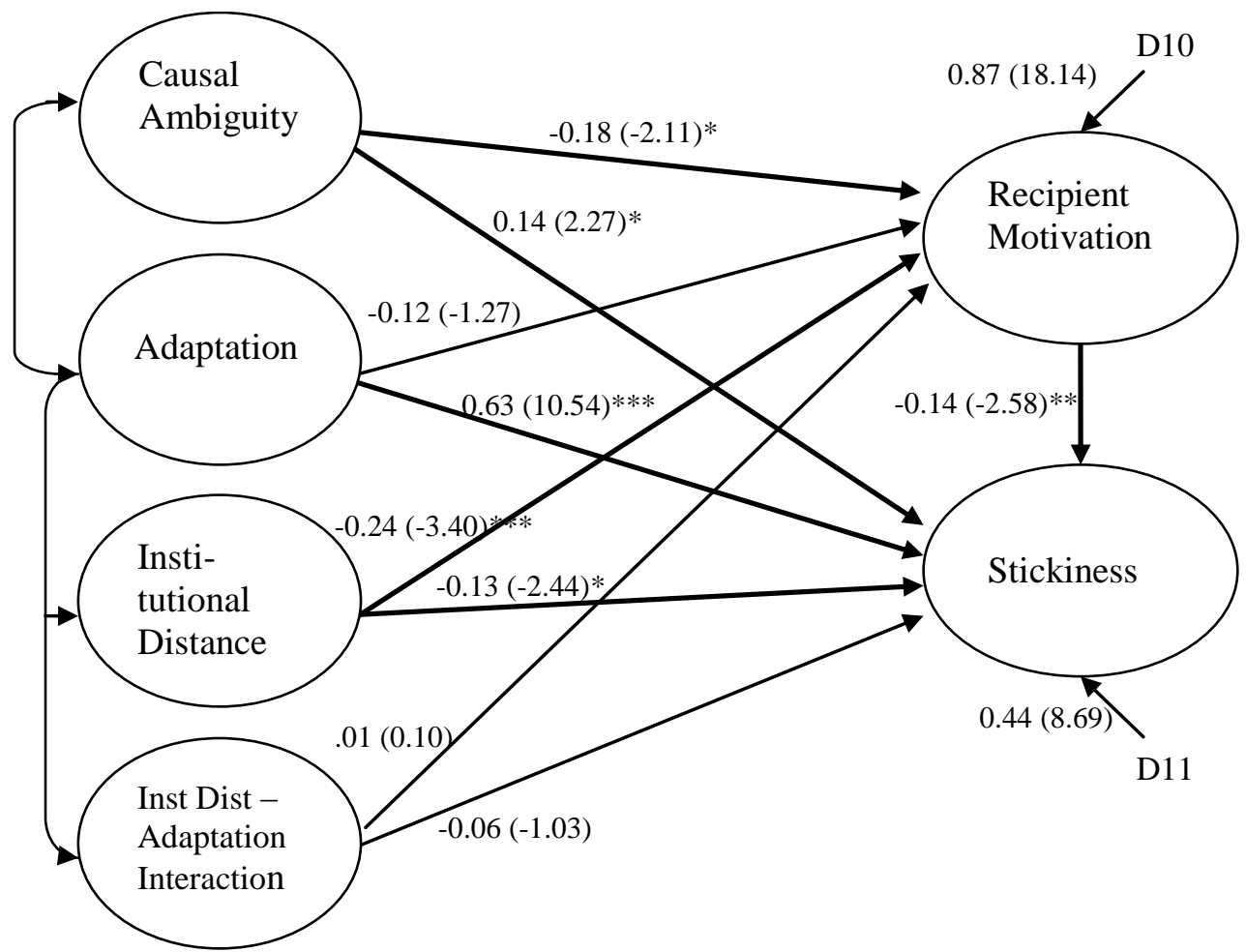

Chi-square is 4.69 with 2 degree of freedom for a p value of .10 , RMSEA=.089, CFI=.989

Bold indicates significant and predicted direction. $* * * \mathrm{p}<.001, * * \mathrm{p}<.01, * \mathrm{p}<.05$

$\mathrm{t}$ statistics are in parentheses.

Table 3: Summary of the Magnitude and Significance of Hypothesized Structural Relationships 
Stickiness and Adaptation in Cross-Border Knowledge Transfers

\begin{tabular}{|c|c|c|c|}
\hline & & Coefficient & Error \\
\hline Hyp 1: Adaptation $\rightarrow$ Recipient Motivation & + & -.119 & .094 \\
\hline Hyp 2: Recipient Motivation $\rightarrow$ Stickiness & - & $-.142 * *$ & .055 \\
\hline Hyp 3: Adaptation $\rightarrow$ Stickiness & - & $.628 * * *$ & .060 \\
\hline $\begin{array}{l}\text { Hyp 4: Recipient Motivation mediates between } \\
\text { Adaptation and Stickiness }\end{array}$ & & \multicolumn{2}{|c|}{ Indirect effect .03 (see table 4$)$} \\
\hline $\begin{array}{l}\text { Hyp 5: Institutional Distance } \rightarrow \text { Recipient } \\
\text { Motivation }\end{array}$ & - & $-.244 * * *$ & .072 \\
\hline Hyp 6: Institutional Distance $\rightarrow$ Stickiness & + & $-.132 *$ & .054 \\
\hline $\begin{array}{l}\text { Hyp 7: Institutional Distance/Adaptation } \\
\text { Interaction } \rightarrow \text { Recipient Motivation }\end{array}$ & + & .008 & .081 \\
\hline $\begin{array}{l}\text { Hyp 8: Institutional Distance/Adaptation } \\
\text { Interaction } \rightarrow \text { Stickiness }\end{array}$ & - & -.059 & .057 \\
\hline
\end{tabular}

Table 4: Decomposition of Effects

\begin{tabular}{lcc}
\hline \multicolumn{1}{c}{ Causal Variable } & \multicolumn{2}{c}{ Endogenous Variable } \\
\cline { 2 - 3 } & Recipient Motivation & Stickiness \\
\hline Causal Ambiguity & $-.18^{*}$ & $.14^{*}$ \\
\hline Direct Effect & -- & .03 \\
Indirect Effect via Recipient Motivation & --- & .17 \\
$\quad$ Total Effect & & $.63 * * *$ \\
Adaptation & -.12 & .02 \\
$\quad$ Direct Effect & --- & .65 \\
$\quad$ Indirect Effect via Recipient Motivation & --- & $-.13^{*}$ \\
Total Effect & & $.03 *$ \\
Institutional Distance & $-.24 * * *$ & -.10 \\
$\quad$ Direct Effect & --- & \\
Indirect Effect via Recipient Motivation & --- & -.06 \\
Total Effect & & .00 \\
Institutional Distance by Adaptation & .01 & -.06 \\
\hline Direct Effect & --- &
\end{tabular}




\section{References}

Anand, Jaideep \& Bruce Kogut. 1997. Technological Capabilities of Countries, Firm Rivalry and Foreign Direct Investment. Journal of International Business Studies, 28(3): 445-65.

Anderson, J.C. \& D.W. Gerbing. 1988. Some Methods for Respecifying Measurement Models to Obtain Unidimensional Construct Measurement. Journal of Marketing Research, 19: 453-460.

Andersson, U., M. Forsgren, \& T. Pedersen. 2001. Subsidiary Performance in MNCs: The Importance of Technology Embeddedness. International Business Review, 10(1): 3-23.

Anonymous. 1999. Apprenticeship Agreement: 2. Great Harvest Bread Co.

Anonymous. 1990. Objects of Desire. The Economist: 95.

Anonymous. 1997. Xerox Makes Copies. Financial Times.

Argote, Linda \& Paul Ingram. 2000. Knowledge Transfer: A Basis for the Competitive Advantage of Firms. Organizational Behavior and Human Decision Processes, 82(1): 1-8.

Armor, D. J. 1974. Theta Reliability and Factor Scaling.In Costner, H.L., editor, Sociological Methodology 1973-1974. San Francisco: Jossey-Bass.

Barkema, Harry G., John H.J. Bell, \& Johannes M. Pennings. 1996. Foreign Entry, Cultural Barriers, and Learning. Strategic Management Journal, 17: 151-66.

Bartlett, Christopher A. \& Sumantra Ghoshal. 1989. Managing Across Borders: The Transnational Solution. Boston, MA: Harvard Business School Press.

Bradach, Jeffrey L. 1998. Franchise Organizations. Boston: Harvard Business School Press.

Buckley, P.J. \& M.C. Casson. 1976. The Future of the Multinational Enterprise. London: MacMillan.

Burgelman, R A. 1983. A Process Model of Internal Corporate Venturing in the Diversified Major Firm. Administrative Science Quarterly, 28: 223-44.

Buzzell, Robert D. 1968. Can You Standardize Multinational Marketing? Harvard Business Review(November-December): 102-13.

Carmines, Edward G. \& Richard A. Zeller. 1979. Reliability and Validity Assessment. Beverly Hills: SAGE.

Cui, Geng \& Qiming Liu. 2001. Executive Insights: Emerging Market Segments in a Transitional Economy: A Study of Urban Consumers in China. Journal of International Marketing, 9(1): 84106.

DiMaggio, Paul J. \& Walter W. Powell. 1983. The Iron Cage Revisited: Institutional Isomorphism and Collective Rationality in Organizational Fields. American Sociological Review, 48: 147-60.

Douglas, Susan P. \& Yoram Wind. 1987. The Myth of Globalization. Columbia Journal of World Business, 22(Winter): 19-29.

Dunning, J.H. 1977. Trade, Location of Economic Activity and the MNE: A Search for an Eclectic Approach.In Ohlin, B., P.O. Hesselborn, \& P.M. Wijkman, editors, The International Allocation of Economic Activity. New York: Holmes \& Meier.

Eisenhardt, K.M. \& J.A. Martin. 2000. Dynamic Capabilities: What Are They? Strategic Management Journal, 21: 1105-21.

Galbraith, Craig S. 1990. Transferring Core Manufacturing Technologies in High Tech Firms. California Management Review, 32(4(Summer)): 56-70.

Gerbing, David W. \& James C. Anderson. 1988. An Updated Paradigm for Scale Development Incorporating Unidimensionality and Its Assessment. Journal of Marketing Research, XXV(May): 186-92.

Gielens, Katrijn \& Marnik G. Dekimpe. 2001. Do International Entry Decisions of Retail Chains Matter in the Long Run? International Journal of Research in Marketing, 18: 235-59.

Gilovich, T. 1991. How We Know What Isn't So: The Fallibility of Human Reason in Everyday Life. New York: Free Press.

Griffith, David A., Michael Y. Hu, \& John K. Ryans, Jr. 2000. Process Standardization Across Intra and Inter-Cultural Relationships. Journal of International Business Studies, 31(2): 303-24. 
Gupta, A. K. \& V. Govindarajan. 2000. Knowledge Flows Within Multinational Corporations. Strategic Management Journal, 21(4): 473-96.

Hannon, John M., Ing Chung Huang, \& Bih Shiaw Jaw. 1995. International Human Resource Strategy and Its Determinants: The Case of Subsidiaries in Taiwan. Journal of International Business Studies, 26(3): 531-54.

Hayes, Robert H \& Kim B. Clark. 1985. Exploring the Sources of Productivity Differences at the Factory Level. NY: Wiley.

Hofstede, G. 1991. Cultures and Organizations: Software of the Mind. Berkshire, U.K.: McGraw-Hill.

Hymer, S.H. 1976. The International Operations of National Firms: A Study of Direct Investment. Cambridge, MA: MIT Press.

Iansiti, Marco. 1998. Technology Integration : Making Critical Choices in a Dynamic World. Boston, Mass.: Harvard Business School Press.

Jensen, Robert James, Gabriel Szulanski, \& Michael V. Casaburi. 2004. Templates and the Effectiveness of Knowledge Transfer: An Empirical Investigation of the Effects of Templates and the Mechanisms of Template Operation. Working paper.

Kashani, Kamran. 1989. Beware the Pitfalls of Global Marketing. Harvard Business Review, 67(September-October): 91-98.

Katz, Ralph \& Thomas J. Allen. 1982. Investigating the Not Invented Here (NIH) Syndrome: A Look at the Performance, Tenure, and Communication Patterns of 50 R\&D Project Groups. $R \& D$ Management, 12(1): 7-19.

Kerwin, Kathleen \& David Woodruff. 1992. Can Olds Hitch its Wagon to Saturn's Star?, Business Week.

Kirkman, B.L., C.B. Gibson, \& D.L. Shapiro. 2001. "Exporting" Teams: Enhancing the Implementation and Effectiveness of Work Teams in Global Affiliates. Organizational Dynamics, 30(1): 12-29.

Kline, Rex B. 1998. Principles and Practice of Structural Equation Modeling. New York: The Guildford Press.

Kogut, Bruce. 1993. Learning, or the Importance of Being Inert: Country Imprinting and International Competition.In Ghoshal, S. \& D.E. Westney, editors, Organizational Theory and the Multinational Corporation. New York: St. Martin's Press.

Kogut, Bruce \& Harbir Singh. 1988. The Effect of National Culture on the Choice of Entry Mode. Journal of International Business Studies, 19(3): 411-32.

Kogut, Bruce \& U. Zander. 1993. Knowledge of the Firm and the Evolutionary Theory of the Multinational Enterprise. Journal of International Business Studies, 24: 625-46.

Kostova, T. 1999. Transnational Transfer of Strategic Organizational Practices: A Contextual Perspective. Academy of Management Review, 24: 308-24.

Kostova, Tatiana \& Kendall Roth. 2002. Adoption of an Organizational Practice by Subsidiaries of Multinational Corporations: Institutional and Relational Effects. Academy of Management Journal, 45(1): 215-33.

Kostova, Tatiana \& Srilata Zaheer. 1999. Organizational Legitimacy under Conditions of Complexity: The Case of The Multinational Enterprise. Academy of Management Review, 24(1): 64-81.

Kramer, Roderick M. 1999. Trust and Distrust in Organizations: Emerging Perspectives, Enduring Questions. Annual Review of Psychology, 50: 569-98.

Lemak, David J. \& Wiboon Arunthanes. 1997. Global Business Strategy: A Contingency Approach. Multinational Business Review, 5(1): 26-37.

Leonard-Barton, Dorothy. 1990. A Dual Methodology for Case Studies: Synergistic Use of a Longitudinal Single Site with Replicated Multiple Sites. Organization Science, 1(3 (August)): 248-66.

Leonard-Barton, Dorothy. 1988. Implementation as Mutual Adaptation of Technology and Organization. Research Policy, 17 (5 (October)): 251-67.

Lippman, S. A. \& R. P. Rumelt. 1982. Uncertain Imitability: An Analysis of Interfirm Differences in Efficiency Under Competition. Bell Journal of Economics, 13: 418-38. 
Luo, Yadong. 2000. Determinants of Local Responsiveness: Perspectives from Foreign Subsidiaries in an Emerging Market. Journal of Management, 27: 451-77.

March, James \& Herbert Simon. 1958. Organizations. New York.

McDonald, Chris J. 1998. The Evolution of Intel's Copy EXACTLY! Technology Transfer Method. Intel Technology Journal(4): http://www.intel.com/technology/itj/q41998/articles/art_2.htm.

Meyer, John \& Brian Rowan. 1977. Institutionalized Organizations: Formal Structure as Myth and Ceremony. American Journal of Sociology, 83: 340-61.

Morosini, Piero, Scott Shane, \& Harbir Singh. 1998. National Cultural Distance and Cross-Border Acquisition Performance. Journal of International Business Studies, 29(1): 137-58.

Muchinsky, P. 1977. An Intraorganizational Analysis of the Roberts and O'Reilly Organizational Communication Questionnaire. Journal of Applied Psychology, 62: 184-88.

Nelson, Richard \& Sidney Winter. 1982. An Evolutionary Theory of Economic Change. Cambridge: Belknap Press.

Nohria, Nitin \& Sumantra Ghoshal. 1997. The Differentiated Network. San Francisco: Jossey-Bass Publishers.

Nunnally, Jum C. 1978. Psychometric Theory. Second ed. New York: McGraw-Hill Book Company.

O'Dell, C.S., C.J. Grayson, \& N. Essaides. 1998. If Only We Knew What We Know: The Transfer of Internal Knowledge and Best Practice. New York: Free Press.

Onkvisit, Sak \& John J. Shaw. 1987. Standardized International Advertising: A Review and Critical Evaluation of the Theoretical and Empirical Evidence. Columbia Journal of World Business, 22(3): 43-55.

Orru, M., N. Bighart, \& G. Hamilton. 1991. Organizational Isomorphism in East Asia.In Powell, Walter W. \& Paul J. DiMaggio, editors, The New Institutionalism in Organizational Analysis. Chicago: University of Chicago Press.

Park, S.H. \& G.R. Ungson. 1997. The Effect of National Culture, Organizational Complementarity, and Economic Motivation on Joint Venture Dissolution. Academy of Management Journal, 40(2): 279-307.

Penrose, Edith Tilton. 1959. The Theory of Growth of the Firm. London: Basil Blackwell.

Ping, R.A. 1995. A Parsimonious Estimating Technique for Interaction and Quadratic Latent Variables. Journal of Marketing Research, 32: 336-347.

Prahalad, C.K. \& Y.L. Doz. 1987. The Multinational Mission: Balancing Local Demands and Global Vision. New York: Free Press.

Ramarapu, Sangeeta, John E. Timmerman, \& Narender Ramarapu. 1999. Choosing Between Globalization and Localization as a Strategic Thrust for Your International Marketing Effort. Journal of Marketing Theory and Practice, 7(2): 97-105.

Roberts, K. \& C. O'Reilly. 1974. Measuring Organizational Communication. Journal of Applied Psychology, 59: 321-26.

Rosenzweig, Philip M. \& Nitin Nohria. 1994. Influences on Human Resource Management Practices in Multinational Corporations. Journal of International Business Studies, 25(2): 229-51.

Rumelt, R. 1984. Toward a strategic theory of the firm.In Lamb, R., editor, Competitive Strategic Management. Englewood Cliffs: Prentice Hall.

Samiee, Saeed \& Kendall Roth. 1992. The Influence of Global Marketing Standardization on Performance. Journal of Marketing, 56(2): 1+.

Scott, W. Richard. 2001. Institutions and Organizations. Second ed. Thousand Oaks, CA: Sage.

Seid, Michael \& Dave Thomas. 2000. Franchising for Dummies. Foster City, CA: IDG Books Worldwide.

Selznick, Philip. 1957. Leadership in Administration: A Sociological Interpretation. New York: Harper \& Row.

Shannon, C. E. \& W. Weaver. 1949. The Mathematical Theory of Communication. Chicago: Illinois: University of Illinois Press. 
Sorenson, Ralph Z. \& Ulrich E. Weichmann. 1975. How Multinationals View Marketing Standardization. Harvard Business Review, 53(May-June): 38-40,42-44,48,50,54,166-67.

Sorge, Arndt. 1991. Strategic Fit and the Societal Effect: Interpreting Cross-National Comparisons of Technology, Organization and Human Resources. Organization Studies, 12(2): 161-90.

Szulanski, G. 2000. The Process of Knowledge Ttransfer: A Diachronic Analysis of Stickiness. Organizational Behavior and Human Decision Processes, 82: 9-27.

Szulanski, Gabriel. 1996. Exploring Internal Stickiness: Impediments to the Transfer of Best Practice Within the Firm. Strategic Management Journal, 17(Winter Special Issue): 27-43.

Teece, David, Gary Pisano, \& Amy Shuen. 1997. Dynamic Capabilities and Strategic Management. Strategic Management Journal, 18(7): 509-33.

Westney, D. Eleanor. 1987. Imitation and Innovation: The Transfer of Western Organizational Patterns to Meiji Japan. First ed. Cambridge, Massachusetts: Harvard University Press.

Whitley, R. 1992. The Social Construction of Organizations and Markets: The Competitive Analysis of Business Recipes.In Reed, M. \& M. Hughes, editors, New Directions in Organization Theory and Analysis. Newbury Park, CA: Sage.

Winter, Sidney G. 1995. Four Rs of Profitability: Rents, Resources, Routines and Replication.In Montgomery, Cynthia A., editor, Resource-Based and Evolutionary Theories of the Firm: Towards a Synthesis. Norwell, MA: Kluwer Academic Publishers.

Winter, Sidney G. \& Gabriel Szulanski. 2001. Replication as Strategy. Organization Science, 12(6): 73043.

Zaheer, Srilata. 1995. Overcoming the Liability of Foreignness. Academy of Management Journal, 38(2): 341-63.

Zaltman, Gerald, Robert Duncan, \& Jonny Holbek. 1973. Innovations and Organizations. New York: John Wiley and Sons.

Zander, Udo \& Bruce Kogut. 1995. Knowledge and the Speed of the Transfer and Imitation of Organizational Capabilities: An Empirical Test. Organization Science, 6(1 (January-February)): 76-92.

Zeigarnik, B. 1967. On Finished and Unfinished Tasks.In Ellis, W.D., editor, A Source Book of Gestalt Psychology. New York: Humanities Press.

Zeller, Richard A. \& Edward G. Carmines. 1980. Measurement in the Social Sciences: The Link between Theory and Data. Cambridge: Cambridge University Press.

\section{Appendix - Operationalization of Variables}

- Each sentence in the description of the scales below is the full text of the question as it appears in the questionnaire.

- $\quad$ Sections in brackets $\langle<>>$ indicate text which was personalized for each different transfer and unit, i.e.; the names of the units and practices were specific to the transfer in question.

- $\quad$ Unless otherwise indicated, answers were scored using the default scale (Y! $\quad \mathrm{Y} \quad \mathrm{O} \quad \mathrm{N} \quad \mathbf{N}$ !).

- Key for the default scale: Y!="Yes!"; Y ="yes, but"; o ="no opinion", N ="no, not really", N!="No!"

- The overall score for each scale was computed by adding the standardized scores obtained from each question.

Stickiness-Implementation $(\alpha=.84$, Items $=18)$ default scale unless indicated $<<$ recipient $>>$ recognized $<<$ source $>>$ 's expertise on $<<$ practice $>>$. The transfer of $<<$ practice $>>$ from $<<$ source $>>$ to $<<$ recipient $>>$ disrupted $<<$ source $>>$ normal operations. $<<$ Recipient $>>$ could not free personnel from regular operations so that it could be properly trained. Communication of transfer related information broke down within $<<$ recipient $>>$. <<Recipient $>>$ was able to recognize inadequacies in $<<$ source $>>$ 's offerings. $<<$ Recipient $>>$ knew what questions to ask $<<$ source $>>$. $<<$ Recipient $\rangle>$ knew how to recognize its requirements for $<<$ practice $>>$. $<<$ Source $>>$ turned out to be less knowledgeable of the $<<$ practice $>>$ than it appeared before the transfer was decided. Much of what <<recipient $>>$ should have done during the transfer was eventually completed by $<<$ source $>>$. $<<$ Source $>>$ understood $<<$ recipient $>>$ 's unique situation. All aspects of the transfer of $<<$ practice $>>$ 


\section{Stickiness and Adaptation in Cross-Border Knowledge Transfers}

from $<<$ source $>>$ to $<<$ recipient $>>$ were carefully planned. Initially $<<$ recipient $>>$ 'spoon fed' the $<<$ practice $>>$ with carefully selected personnel and raw material until it got up to speed. At first $<<$ recipient $>>$ measured performance more often than usual, sometimes reacting too briskly to transient declines in performance. Some people left $<<$ recipient $>>$ after having been trained for the new role in the $\langle<$ practice $\rangle$, forcing $<<$ recipient $\rangle>$ to hire hastily a replacement and train it 'on the fly.' Some people turned out to be poorly qualified to perform their new role in the $<<$ practice $>>$, forcing $<<$ recipient $>>$ to hire hastily a replacement and train it 'on the fly.' The $<<$ practice $>>$ had unsatisfactory side effects which <<recipient $>>$ had to correct. Outside experts (from $<<$ source >>, other units, or external consultants) could answer questions and solve problems about their specialty but did not have an overall perspective on the $\langle<$ practice $\rangle$. Teams put together to help $\langle<$ recipient $\rangle>$ to get up to speed with the $<<$ practice $>>$ disbanded because their members had to attend to other pressing tasks.

Adaptation ( $\alpha=.76$, Items $=7$ ) default scale unless indicated Compared to that of $<<$ source $>>,<<$ recipient $>>$ 's $<<$ practice $>>$ is: (circle one option) $\mathbf{1}=$ "Exactly the same"; $\mathbf{2}=$ "Essentially the same"; $\mathbf{3}$ = "Slightly modified", 4 = "Markedly modified", $5=$ "Completely different". $\langle<$ Recipient $\rangle>$ performed unnecessary modifications to the <<practice $\rangle>$. $\langle<$ Recipient $\rangle>$ modified the $<<$ practice $>>$ in ways contrary to expert's advice. $<<$ Recipient $>>$ 's environment turned out to be different from that of $\langle<$ source $\rangle>$ forcing $\langle<$ recipient $\rangle>$ to make unforeseen changes to $<<$ practice $\rangle>$. The $<<$ practice $\rangle>$ had to be adapted to make it workable at $\langle<$ recipient $>>$. A practice could be thought of as composed of separable modules, some essential for its functioning, some not. Each of these modules may be included or may be excluded during a transfer. Thinking about the <<practice>> as a set of modules, please circle the most correct assertion: $\mathbf{1}=$ "All modules have been transferred"; $\mathbf{2}=$ "Only selected, but all the essential modules have been transferred"; $\mathbf{3}=$ "Only the essential modules have been transferred", $4=$ "Only selected modules, some essential some not, have been transferred", $\mathbf{5}=$ "None of the modules have been transferred". Some components for the $\langle<$ practice $\rangle>$ were replaced by existing ones at $<<$ recipient $>>$.

Recipient Motivation ( $\alpha=.93$, Items $=14$ ) binary items Recipient saw benefit in: measuring its own performance; comparing it with the performance of other units; understanding its own practices; absorbing «source»'s understanding; analyzing the feasibility of adopting «practice»; communicating its needs to «source»; planning the transfer; implementing the systems and facilities for «practice», assigning personnel full time to the transfer; assigning personnel to be trained in «practice»; understanding the implications of the transfer; troubleshooting «practice»; insuring that its people knew their jobs; insuring that its people consented to keep doing their jobs.

Causal Ambiguity $(\alpha=.86$, Items $=8)$ default scale The limits of the «practice» are fully specified. With the «practice», we know why a given action results in a given outcome. When a problem surfaced with the «practice», the precise reasons for failure could not be articulated even after the event. There is a precise list of the skills, resources and prerequisites necessary for successfully performing the «practice». It is well known how the components of that list interact to produce «practice»'s output. Operating procedures for the «practice» are available. Useful manuals for the «practice» are available. Existing work manuals and operating procedures describe precisely what people working in the «practice» actually do. 